\title{
Role of autophagy in breast cancer and breast cancer stem cells (Review)
}

\author{
YANYAN HAN $^{1}$, SHUJUN FAN $^{1}$, TAO QIN $^{1}$, JINFENG YANG $^{1}$, \\ YAN SUN ${ }^{1}$, YING LU ${ }^{1,2}$, JUN MAO ${ }^{1}$ and LIANHONG LI ${ }^{1}$ \\ ${ }^{1}$ Department of Pathology, and ${ }^{2}$ Teaching Laboratory of Morphology, \\ Dalian Medical University, Liaoning 116044, P.R. China
}

Received September 7, 2017; Accepted January 9, 2018

DOI: $10.3892 /$ ijo.2018.4270

\begin{abstract}
Autophagy is a key catabolic process, in which cytosolic cargo is engulfed by the formation of a double membrane and then degraded through the fusing of autophagosomes with lysosomes. Autophagy is a constitutively active, evolutionarily conserved, catabolic process important for the maintenance of homeostasis in cellular stress responses and cell survival. Although the mechanisms of autophagy have not yet been fully elucidated, emerging evidence suggests that it plays a dual role in breast cancer and in maintaining the activity of breast cancer stem cells (CSCs). However, it may play a complex role in breast CSC therapy. Breast CSCs, a population of cells with the ability to self-renew, differentiate, and initiate and sustain tumor growth, play an essential role in cancer recurrence, anticancer resistance and metastasis. In addition, the elucidation of the association between autophagy and apoptosis in the tumor context is crucial in order to better address appropriate therapy strategies. In the present review, a summary of the mechanisms and roles of autophagy in breast cancer and CSCs is presented. The potential value of such autophagy modulators in the development of novel breast cancer therapies is discussed.
\end{abstract}

\section{Contents}

1. Introduction

2. Functions and mechanisms of autophagy

3. Breast cancer stem cells

4. Autophagy and the growth of breast cancer and breast cancer stem cells

5. Autophagy and apoptosis in breast cancer and breast cancer stem cells

6. Autophagy and metastasis in breast cancer and breast cancer stem cells

Correspondence to: Dr Lianhong Li, Department of Pathology, Dalian Medical University, 9 Lvshun South Road, Liaoning 116044, P.R. China

E-mail: lilianhong@dlmedu.edu.cn

Key words: autophagy, breast cancer, breast cancer stem cells
7. Characteristics of autophagy in breast cancer and breast cancer stem cells

8. Autophagy-related molecules in breast cancer and cancer stem cells

9. Inhibitors of autophagy in breast cancer and cancer stem cells

10. Autophagy and different types of breast cancer

11. Conclusion

\section{Introduction}

Breast cancer is the most common and aggressive tumor type affecting women. The typical characteristics of the majority of patients with breast cancer are that they express receptors for estrogen (ER) and progesterone receptor (PR) and respond to hormonal therapy (1). Hormonal therapy, chemical therapy and radiotherapy have led to increased survival rates. However, the occurrence rate of breast cancer has still increased. Triplenegative breast cancer (TNBC), characterized by the lack of ER, PR and human epidermal growth factor receptor (HER)-2 (ErbB-2, C-erbB2 or Her2/neu) expression, is insensitive to hormonal therapy, chemotherapy and radiotherapy, and is more likely to result in anticancer resistance. Therefore, the development of novel therapeutic strategies is critical for these patients. Recent studies have suggested that breast cancer stem cells (CSCs), a small subpopulation of cells, have the ability to self-renew and differentiate into the entire tumor. They are resistant to chemotherapy and radiotherapy, and can result in tumor recurrence, even following surgery (1). Hence, there is a need for the development of novel strategies that target these cells. Cell death is a complex phenomenon in multicellular organisms, which can occur under both physiological and pathological conditions. Apoptosis, autophagy and necrosis are three common cell death processes. It is generally recognized that necrosis is a form of non-programmed cell death and is independent of the caspase family. Apoptosis and autophagy are programmed cell death pathways. The 2016 Noble Prize for Physiology or Medicine was awarded to Dr Yoshinori Ohsumi, due to his work on the mechanisms of autophagy. Autophagy, a conserved catabolic pathway, can promote cell homeostasis during nutrient deprivation (2). Recent data have illustrated that mutations in genes involved in autophagy play a critical role in 
the pathogenesis of diverse diseases, including cancer (3-6). Specifically, autophagy has been shown to be associated with CSC differentiation. However, the functional importance of autophagy remains unclear in breast cancer and CSCs. Thus, the present review aimed to elucidate the role and related mechanisms of autophagy in breast cancer and breast CSCs. This topic may aid in the development of a novel therapeutic strategy for breast cancer in the future.

\section{Functions and mechanisms of autophagy}

Three main types of autophagy are currently recognized: Micro, macro and chaperone-dependent autophagy. These processes are made possible due to specific enzymes and autophagy-related genes (ATGs) (7). Within this review, the term autophagy refers to macroautophagy, the process through which unnecessary or dysfunctional cellular components are removed via the union of lysosomes and autophagosomes to create autolysosomes. Autophagy levels are usually lower under normal conditions compared with starvation or nutrition-deficiency conditions. Autophagy can only be induced extensively by internal or external stimulation. It can be notably inhibited by knocking down ATGs, which leads to the damaged proteins and cell organelles, such as the mitochondria, not being removed, thus creating a toxic environment that can affect the survival of normal cells. In addition, autophagy provides a supply of metabolic precursors for macromolecular synthesis during nutrient stress. The cytosolic targets of autophagy include proteins, lipid droplets, glycogen, granules, nucleic acids and whole organelles, such as the mitochondria. Autophagy also plays a critical role in sustaining ATP production while under energy failure.

Residues 1-1,375 of the mammalian target of rapamycin (mTOR) are relatively undefined compared with its other sections; however, the N-terminal part is mainly formed by HEAT repetitions (8). The well-defined structure of mTOR consists of the FAT/REB/kinase/FATC domains (Fig. 1). The kinase domain (KD) binds ATP within itself, whereas the FRB domain binds rapamycin-FKB12 within itself. The components of the well-defined parts of mTOR are kinase (joined by ATP), FATC, REB and FAT $(9,10)$. The KD serves as a joint between mTOR and mLST8, playing a considerable role in stabilizing the reaction between mTOR and the receptor (11). Ttil and Tel2 form a supporting platform for mTOR function, and that of many other compounds. The Tel2 part binds to HEAT repeat regions in $\operatorname{mTOR}(12,13)$. DEPTOR binds to mTOR at the FAT domain and inhibits the mTOR function (14). mTOR is part of TORC1 and TORC2, which are both protein structures. Therefore, there are many molecules that are able to affect mTOR function.

The first regulatory stage of autophagy is the de-repression of mTOR. TORC1 (hereafter referred to as the TOR complex) is sensitive to rapamycin. The physiological consequences of mammalian TORC1 deregulation demonstrated that the inhibition of mTOR may be useful in the treatment of cancer (15). mTORC2 can regulate autophagy via Akt-FoxO3 (16,17). mTOR consists of the mTOR catalytic subunit, including the regulatoryassociated protein of mTOR (Raptor), the proline-rich AKT substrate of $40 \mathrm{kDa}$ (PRAS40) and the G protein $\beta$-subunit-like protein (GßL), also known as mLST8 (Fig. 1).
Structures, such as Unc-51-like kinase 1 (ULK1) and FAK-family interacting protein of $200 \mathrm{kDa}$ (FIP200) are formed due to the activation of autophagy-related proteins, which occurs following the inhibition of mTOR (Fig. 2) (18). GTPases can promote, in the activated areas, the departure of mTOR to the external section of the lysosome. Vacuolar ATPase enriches activities associated with amino acids as a supportive function, binding lysosomes and GTPases (19-21). Inactive mTORC1 does not generate a matrix, such as the transcription factor EB phosphorylation, being able to regulate ATG functions when moving to the nucleus (22).

The phagophore is dependent on the combined action of a number of factors, including Beclin1, UV radiation resistance associated (UVRAG), Bif-1, autophagy and beclin 1 regulator 1 (AMBRA1), as well as others in its viral version (Fig. 2). The function of the class-III PI3K is critical for vesicle nucleation. ATGs are equally important and control the elongation of vesicles. Two protein structural complexes are required to achieve an increase in the autophagosome membrane: ATG5-ATG12-ATG16 and LC3-PE. These complexes can transform LC3-I to LC3-II in the cytosol, particularly in the autophagosome (23). LC3 can be converted into LC3-I by joining with ATG4, and thereafter LC3-I can be converted into LC3-II by joining ATG7, ATG3 and PE (phosphatidylethanolamine). ATG10 can replace ATG7 in being bound to ATG5, and this enables ATG5 to bind to ATG12. LC3-II is the active form of LC3-I, and can attach to the phagophore membrane.

Certain pathways can regulate mTOR, including adenosine monophosphate-activated protein kinase (AMPK) and PI3K/AKT. mTOR can be considered as a part of the PI3K pathway, which is significant to autophagy. mTOR exerts a crucial effect on autophagy as a downstream component in the signaling pathway of PI3K. Under standard conditions, phosphorylated PI3K phosphorylates AKT, which inhibits tuberous sclerosis complex $1 / 2$ (TSC1/2) and then activates mTOR. Subsequently, mTOR mediates the expression of several autophagy proteins, ultimately suppressing the autophagy process. AMPK plays a fundamental role as a catalyst in the regulation of energy in a cell. It is activated when intracellular ATP levels become lower than normal. Autophagy can be regulated through the AMPK pathway in breast cancer, and inhibition of the AMPK signaling pathway affects the process of autophagy in breast cancer (24). Activated AMPK activates autophagy by targeting the ULK1 complex.

\section{Breast cancer stem cells}

Al-Hajj et al was the first to observe CSCs in cases of breast cancer in 2003 (25). CSCs may be responsible for the recurrence of tumors and metastases, thus affecting the treatment progress (25). CD44, CD24 and aldehyde dehydrogenase (ALDH) are the three main signs of the association of CSCs with breast cancer (26). Indeed, the appearance of CSC markers, such as ALDH, CD44 or CD24, differs among breast cancer molecular subtypes. ALDH has a scattered distribution in each subtype, and tumors of the basal type exhibit a high percentage of CD $44^{+} / \mathrm{CD} 24^{-/ \text {low }}$ cells compared with the luminal type (27). Additionally, CD $44^{+} / \mathrm{CD} 24^{-/ \text {low }}$ cells are predominant in triplenegative breast cancers, resulting in a poor prognosis (28). There 


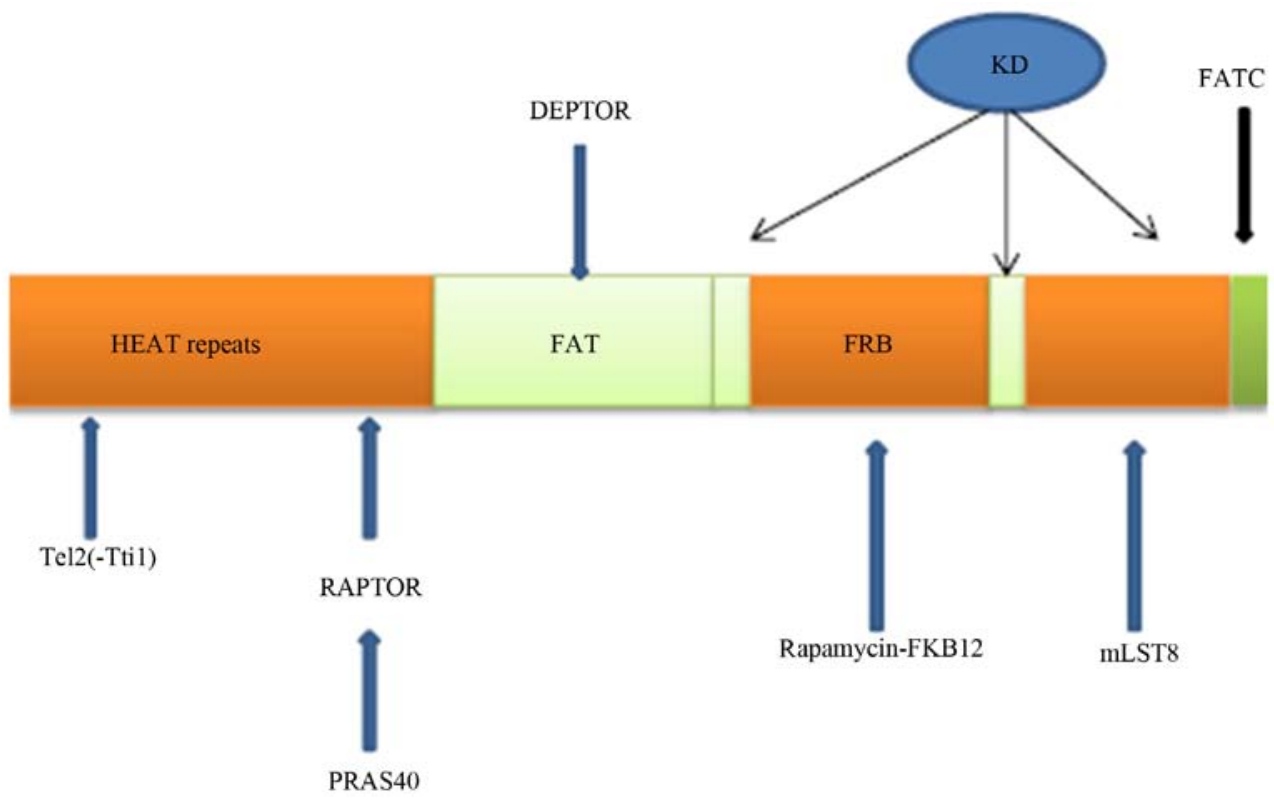

Figure 1. Structure of mammalian target of rapamycin (mTOR). The components of mTOR are marked as to which mTOR domain, or complex protein, they bind to. Components found in both complexes are Tel2, DEPTOR and mLST8. Specific mTORC1 components are RAPTOR and PRAS40 and a specific mTORC2 component is rapamycin-FKB12.

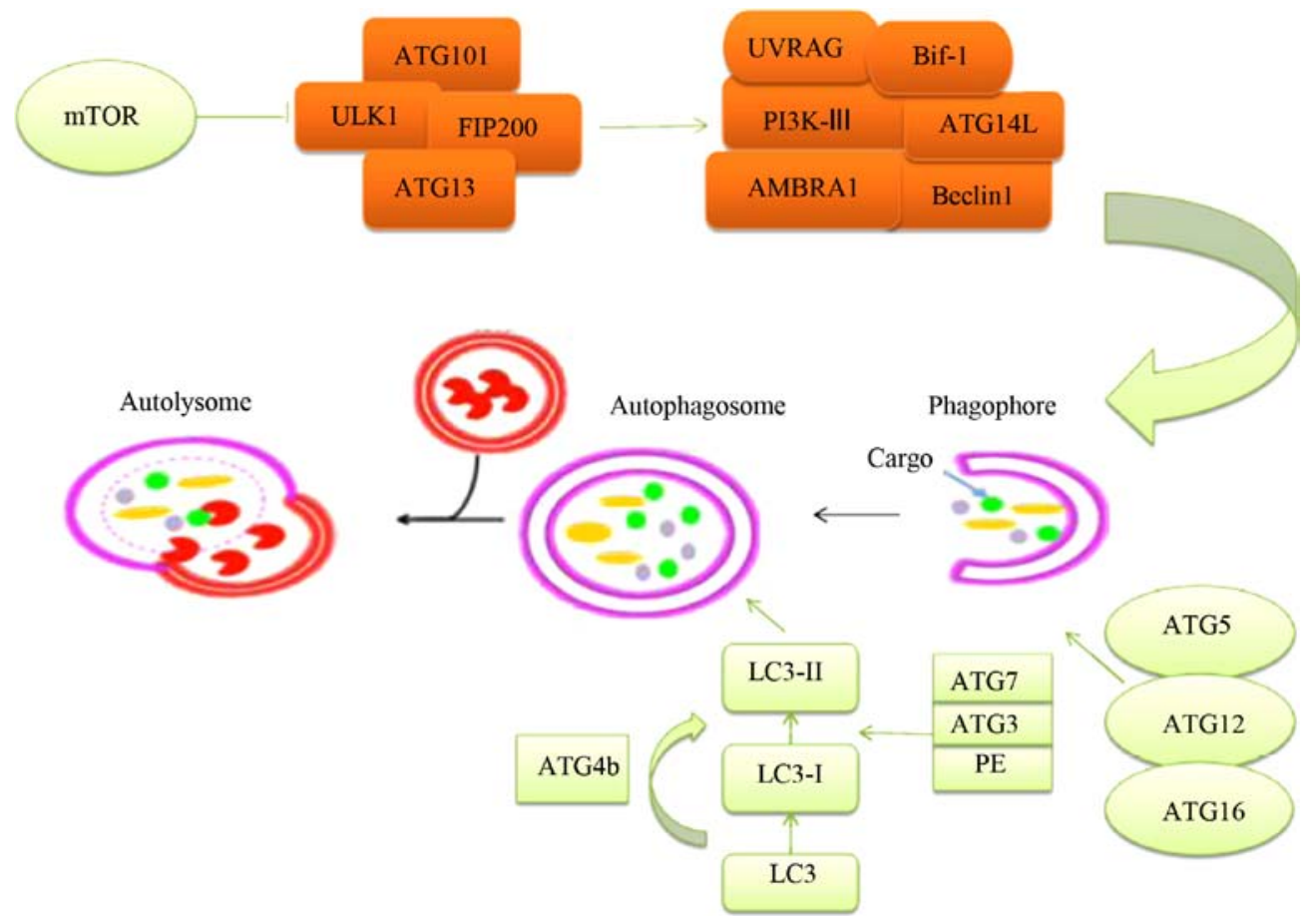

Figure 2. Regulatory mechanisms involved in autophagy. When mammalian target of rapamycin (mTOR) is inhibited, the activation of the ULK1, ATG101, FIP200 and ATG13 protein complex is induced, which can mediate the initiation of autophagy. The generation of a phagophore is regulated by autophagyrelated genes (ATGs). The Beclin1 complexes can be activated by Atg14L and UVRAG/Bif-1, and the latter can induce the formation of autophagosomes in a mutually exclusive manner. Two ubiquitin-like protein conjugation systems are important for phagophore elongation into an autophagosome. Finally, the contents within the autophagosome are degraded when the autophagosome fuses with a lysosome.

are related data to suggest that the $\mathrm{CD} 44 / \mathrm{CD} 24^{+}$phenotype is closely associated with a poor prognosis in early invasive breast cancer (29). Thus, according to the histological type and/ or tumor stage, the relevance of breast CSC markers may vary. They may also be relevant to the differentiation degree of cells within the tumor, which highlights the heterogeneity of the tumor microenvironment (TME).
Cells in the TME, such as endothelial cells, fibroblasts or even mesenchymal stem cells, are thought to regulate breast CSCs, when they secrete different signaling molecules associated with survival, proliferation or differentiation (30). The constant appearance of CSCs in breast cancer has been associated with signaling pathways associated with embryonic development, such as the Notch and hedgehog pathways. 
These proteins promote cellular reproduction and specialization through signaling routes associated with paracrine and autocrine processes (31). Sonic, Indian and Desert are the three types of hedgehog gene in mammals (32). The activation of the smoothened transmembrane protein is promoted by interactions between hedgehog proteins and the Patched transmembrane protein (33). CSCs appear to be sustained due to the hedgehog pathway. Proteins of the Notch type have four transmembrane glycoproteins and five ligands (34). This signaling route is associated with the reproduction and specialization of cells (35). The Notch pathway is activated due to the release of its intracellular domain through the nucleus by proteolytic cleavage, and interaction with receptor extracellular domains. In WNT/ $\beta$-catenin signaling, the transcriptional activator, $\beta$-catenin, is maintained at low levels through continuous degradation. Once WNT binds to the Frizzled receptors, $\beta$-catenin is then released from the multi-protein destruction complex (including APC and GSK-3 $\beta$ ) and translocates from the cytoplasm to the nucleus, thus activating several proliferation-related target genes (32). During development, it controls the fate of the cells; however, in adults it supports tissue self-renewal.

\section{Autophagy and the growth of breast cancer and breast cancer stem cells}

Autophagy is a key factor in cell growth; therefore, the inhibition of autophagy can decrease tumor growth. Cancerassociated fibroblasts (CAFs) play an essential role in malignant cancer progression. Beclin1 and LC3-II/I protein conversion levels in CAFs are higher than those in normal fibroblasts (NFs). CAF autophagy can enhance triple-negative breast cancer (TNBC) cell proliferation (36). In addition, Research has been indicated that anticancer therapy may induce autophagy (37), affecting tumor cell proliferation. Therefore, the combination of autophagy inhibition and chemotherapy may become an effective therapy for breast cancer (37). Chloroquine (CQ), an autophagy inhibitor, removes CSCs via an epigenetic mechanism by altering DNA methylation. CQ causes mitochondrial damage, resulting in excessive oxidative DNA damage and subsequent cell death in TNBC CSCs (38).

\section{Autophagy and apoptosis in breast cancer and breast cancer stem cells}

The characteristics of type I cell death include a reduction in cell volume, the destruction of the cellular cytoskeleton, the condensation and fragmentation of nuclear content, and the formation of apoptotic bodies that are disposed by phagocytes. There are two different pathways that can mediate apoptosis: The receptor pathway and the mitochondrial pathway. It has been indicated that many types of cancer cells may lack death-associated protein kinase (DAPK). Phosphorylated Beclin1 can induce the release of Beclin1 from Bcl-2-related proteins and induce autophagy. The protein cleaved by caspases, Bcl-2, is a negative regulator of Beclin1. This protein can inhibit autophagy and enhance apoptosis. ATG5 is cleaved by calpains to produce an N-terminal ATG5 cleavage product, which is believed to induce cytochrome $c$ release from mitochondria. Full-length Beclin1 and ATG5 oppose this process by regulating the autophagic degradation of active caspase-8 (39). This suggests that autophagy and apoptosis may have the same regulatory factors (Fig. 3).

Cell death and survival are notably complex processes, and both autophagy and apoptosis play significant roles. Based on the aforementioned analysis, we know that there are common regulatory factors between autophagy and apoptosis. In addition, Yousefi et al reported that knocking down ATGs decreased sensitivity to anticancer therapy (40). Lu et al discovered that the inhibition of autophagy enhanced the apoptosis induced by parthenolide in breast cancer (24). Consequently, there is a close association between autophagy and apoptosis. The investigation of this association is critical for the understanding of the mechanisms of autophagy in breast cancer and CSCs.

\section{Autophagy and metastasis in breast cancer and breast cancer stem cells}

Invasion and metastasis are important characteristics of tumors and also increase the risk of cancer. Autophagy provides a survival mechanism that endowes cancer cells with metabolic flexibility, allowing for their survival in nutrient- and oxygen-poor TMEs. Cancer cells tend to metastasize under nutrient- and oxygen-poor conditions. Studies using surrogate markers have identified a close association between increased autophagy and metastasis. Increased punctae staining for microtubule-associated light chain B (LC3B) has been shown to be associated with lymph node metastasis and decreased survival in human breast cancer, whereas melanoma metastases demonstrated increased LC3B staining compared with matched primary tumor samples (4). Moreover, in response to hypoxia and metabolic stress, necrosis frequently occurs in carcinoma in situ, which can enhance inflammation and promote inflammatory cell infiltration, which favors prometastatic immunity $(41,42)$. Autophagy effectively suppresses necrosis and subsequent inflammatory cell infiltration from tumor sites by providing energy and metabolic precursors, and restrains metastasis. Based on this hypothesis, there is a complex interaction between autophagy and metastasis. Epithelial-to-mesenchymal transition (EMT) is important for cancer spreading and dissemination. Two primary regulators of EMT, Snail and Slug, which can promote EMT by inducing the loss of epithelial (E)-cadherin-mediated cell-cell adhesion, are associated with autophagy. Autophagy deficiency has been discovered to promote EMT by stabilizing Twist1 (43). Recently, some studies on autophagy and metastasis have identified novel therapeutic methods. For example, the downregulation of macroautophagy associated with ATG5 by chaperone-regulated autophagy was identified to promote breast cancer cell metastasis (44).

\section{Characteristics of autophagy in breast cancer and breast cancer stem cells}

Characteristics of autophagy in breast cancer. Autophagy plays a significant role in all stages of cancer development. Recently, it was reported that autophagy is a 'double-edged sword'; it can inhibit cancerous growth, and can also suppress inflammation, tissue injury and chromatin instability in the 


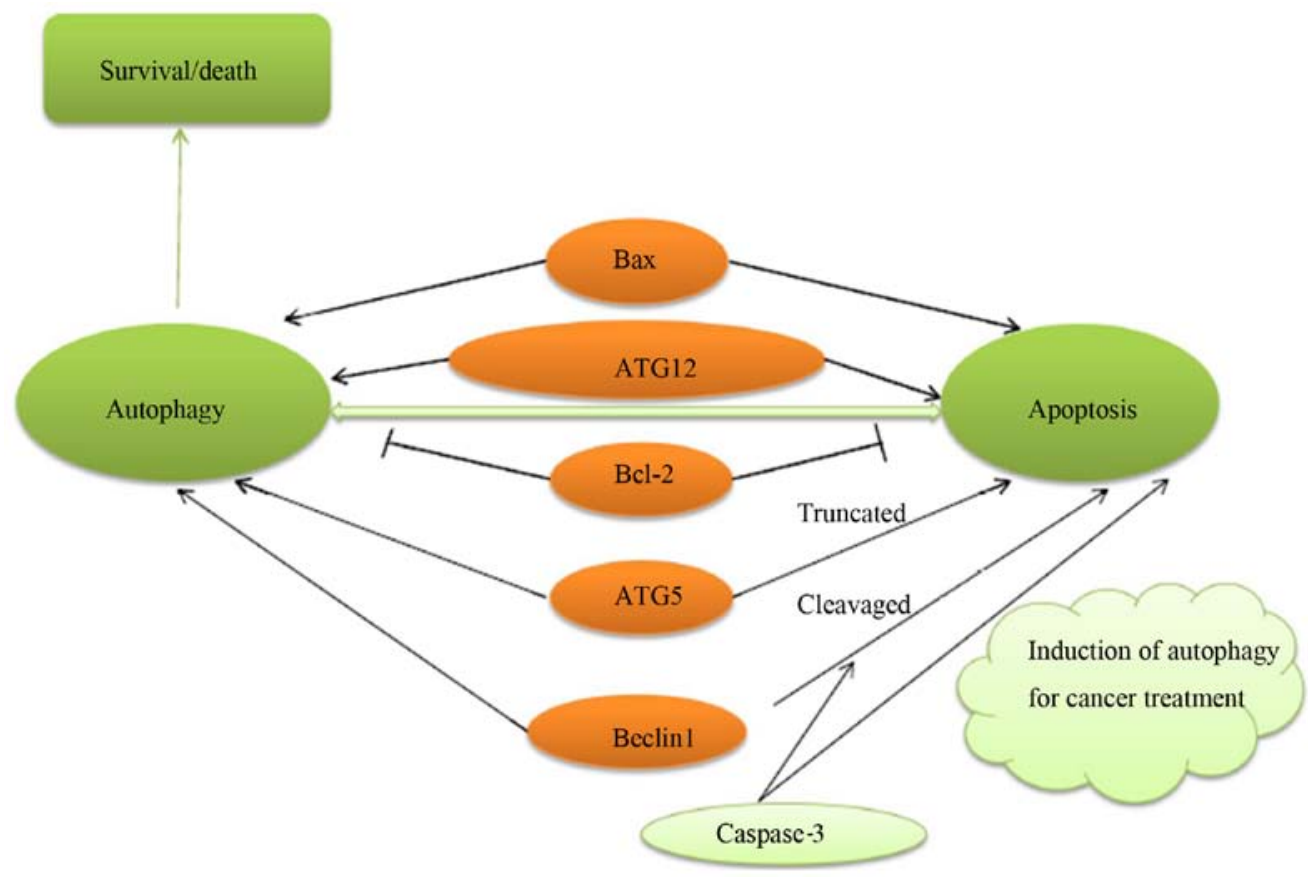

Figure 3. Association between autophagy and apoptosis. Autophagy and apoptosis are regulated by a number of common molecules. The anti-apoptotic members of the Bcl-2 family can interact with Beclin1, which can suppress Beclin1-dependent autophagy. Pro-apoptotic proteins play different roles and can induce autophagy. Moreover, autophagy-related genes (ATGs) can activate apoptosis. Caspase-3 can induce apoptosis via mediating Beclin1, and the cleavage of Beclin1 renders cells sensitive to apoptosis.

initial stages of cancer, which is mostly relative to the formation of cancer. During other stages, autophagy may perform a complex function depending on the internal and external context (39). One of the typical features of cancer is proliferation, which can promote metastasis and lead to nutrient deficiency. Autophagy tends to induce the metastatic process by maintaining and spreading cell survival, and causes the cells to enter a dormant state if they cannot establish stable contact with the extracellular matrix in the new environment (39). However, in fully transformed carcinoma cells, the deficiency of autophagy can facilitate malignant tumor metastasis and neoplasia. Moreover, it may also facilitate breast cancer progression, independent of genotoxic stress and genomic instability. Kongara et al (45) reported that a low expression of Beclin1 was linked to phosphorus (Ser73) accumulation in human breast cancer. When cancer cells are able to be placed under conditions with metabolic and genotoxic stress due to progression and metastasis, and therapy is accepted, autophagy shifts to tumor-promoting mechanisms by maintaining the survival of the tumor cells (46). Hypoxia and acidic material can lead to metabolic pressure, while chemotherapy and radiotherapy lead to genotoxic pressure. Autophagy can decrease sensitivity to anticancer treatments, eliminate organelle damage, DNA fragmentation, and preserve the integrity of the cells. Based on these effects, the inhibition of autophagy can enhance the sensitivity to anticancer therapy.

In mice with autophagy dysfunction, damaged mitochondria and complexes with p62 and ubiquitinated proteins accumulate, which can result in the massive generation of reactive oxygen species (ROS), and can lead to DNA mutation and chromatin condensation (47 and refs therein). Since genetic damage can increase the risk of tumor occurrence, the gene protection mechanism regulated by autophagy is likely to involve the inhibition of tumor development. Under continuous stimulation, tumor cells with autophagy deficiency often fail to sustain their survival processes, leading to chronic death. The chronic death of cells causes an inflammatory response that can further promote the development of cancer. Autophagy dysfunction may induce necrosis and inflammation through the release of pro-inflammatory factors. For example, high mobility group protein B1 (HMGB1), generated by necrotic cells, binds to cell surface receptor of advanced glycation end products (RAGE), which can activate transcription factor nuclear factor (NF)- $\kappa$ B and cause inflammation (48). Similarly, nucleic acids released from necrotic cells stimulate the inflammatory response by activating Toll-like receptors (49). Additionally, excessive autophagy can lead to autophagic death. Under continuous stress and progressive autophagy, cells die due to self-consumption (50), following the high expression of Beclin1 and massive autophagosomes.

Characteristics of autophagy in breast cancer stem cells. Autophagy is considered to be a conserved cellular process, consisting of the response of cells to various external stimuli, such as radiation and the low concentration of oxygen or nutrients. Morever, CSCs are considered to depend on their surroundings to maintain development and growth. Autophagy is also activated by environmental factors, as aforementioned and it affects the surrounding tumor environment, regulating the activity between tumor cells and stromal components, such as fibroblasts, immune cells and endothelial elements. The inhibition of autophagy has been demonstrated to enhance the sensitization of tumor cells to treatment; however, this has not been clearly demonstrated for CSCs. In recent studies, the de-activation of autophagy-related genes in order to inhibit autophagy was observed to decrease the effects of CSCs 


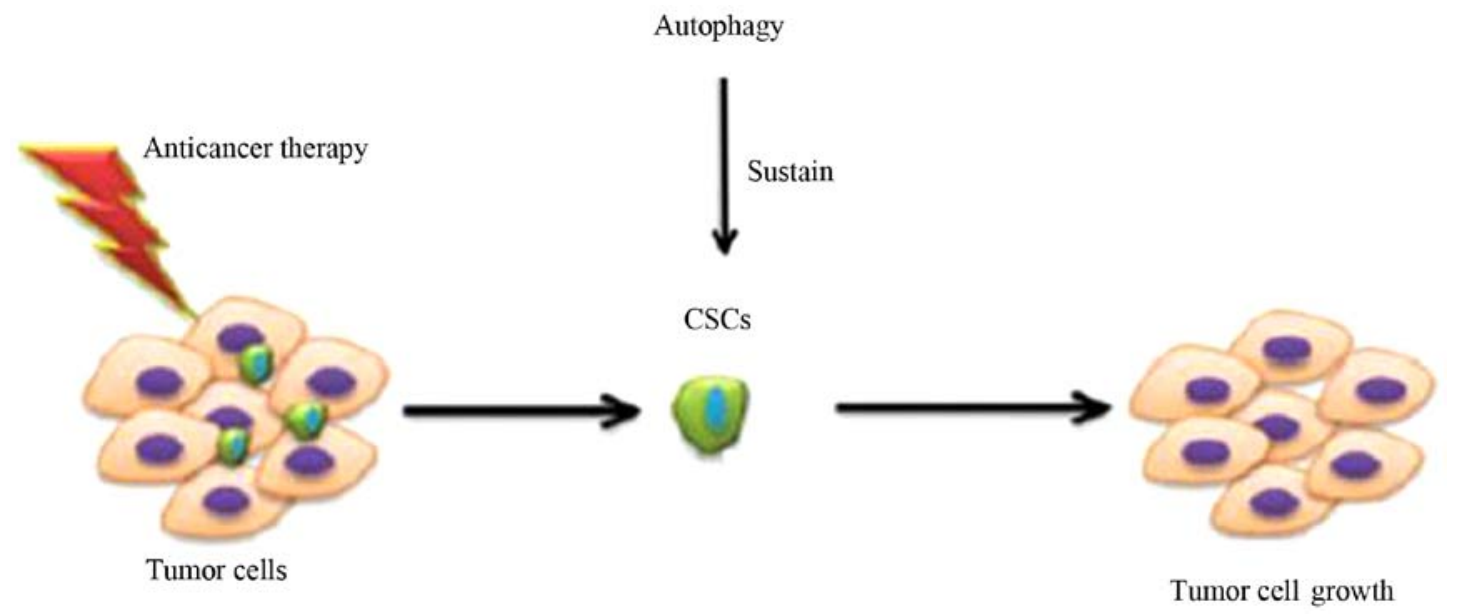

Figure 4. Autophagy and cancer stem cells (CSCs). During anticancer therapy, the process of autophagy can sustain the activity of CSCs, which can facilicate tumor cell growth and can lead to resistance to the effects of the treatment drugs.

$(63,65)$ (Fig. 4). Combining this method with traditional cancer therapies can improve the rate of cancer elimination and curative treatment. It has been demonstrated that autophagy can drive CSC levels in breast cancer (51-53), and that some ATGs, such as Beclin1 and ATG4A, serve a function in sustaining breast CSCs. This is consistent with the theory that autophagy plays a supportive role in CSCs $(52,53)$.

Furthermore, certain studies have focused on breast CSC treatment. Autophagy may play a dual role in the therapeutic process of targeting breast CSCs. For example, Zhao et al discovered that autophagy played a positive role, increasing the sensitivity of glioma stem cells to X-ray radiation (54). Autophagy induced by Rottlerin can promote breast CSC apoptosis $(55,56)$. However, Wei et al found that autophagy inhibited colon CSC apoptosis induced by photodynamic therapy (57). In breast cancer, the inhibition of autophagy can decrease the drug-resistance of breast CSCs, as well as reduce the ability of breast CSCs to form tumors $(55,58)$. Therefore, further research is required to elucidate the complex association between autophagy and breast CSCs.

\section{Autophagy-related molecules in breast cancer and cancer stem cells}

Autophagy plays an important role in breast cancer and breast CSCs, and is controlled by ATGs. Knowing more about the roles of ATGs may be crucial to improving the effectiveness of breast cancer therapy. There are some molecules that can regulate breast cancer, as well as breast CSCs (Table I).

In addition, there are certain pathways that are associated with breast CSCs, which can regulate cellular differentiation and survival and are closely associated with tumors (61). Recent research has indicated that the downstream target of AKT, mTOR, is also essential to breast CSCs (79). Based on these findings, mTOR is a key control point for autophagy. Thus, the PI3K/AKT signaling pathway may play an important role in the autophagy of breast CSCs. Transforming growth factor (TGF)- $\beta$ can be mediated by SMAD2/SMAD3, resulting in the regulation of autophagy. The Wnt signaling pathway may be linked to autophagy, and the inhibition of the Wnt signaling pathway can induce autophagy. Via transcription factor 4
(TCF4), $\beta$-catenin can suppress the formation of autophagic vacuoles, and suppress the expression of p62/SQSTM1 (80). The overexpression of LC3-II and Beclin1 is contrary to the role of the Notch signaling pathway. The inhibition of the hedgehog pathway exerts the same effects as those induced by the inhibition of the Wnt and Notch pathway (81).

\section{Inhibitors of autophagy in breast cancer and cancer stem cells.}

Autophagy may protect the anticancer resistance response of breast cancer cells and maintain the activity of breast CSCs. In addition, autophagy can exert effects on the initiation, proliferation and progression of tumors and CSCs. The inhibition of autophagy can increase cancer cell death. Therefore, it is important to increase our knowledge of inhibitors of autophagy. There are some inhibitors of autophagy (Table II) that can exert an effect on breast cancer and breast CSCs. Understanding their current stage in research and development is essential for breast cancer therapy. In addition, these compounds can suppress autophagy, which could be critical to identifying new therapeutic mechanisms.

In addition, there are other medications that can exert effects on autophagy, including eriocalyxin B (93), tetrandrine (94) and suberoylanilide hydroxamic acid, which is also critical in breast cancer therapy (95). Based on our analysis, the majority of inhibitors of autophagy may play an important role in both breast cancer and breast CSCs. However, further research is required in order to determine whether chloroquine or 3-methyladeninecan can directly inhibit breast cancer cell growth. Therefore, more attention should be paid to the novel therapeutic mechanisms of these autophagy-associated drugs.

\section{Autophagy and different types of breast cancer}

Recent studies have revealed autophagy-dependent pathways in different subtypes of breast cancer. It would thus be helpful to discuss the role of autophagy in breast cancer subtypes.

Autophagy and TNBC. TNBC, a subgroup of tumors, do not express clinically significant levels of ER, PR and HER2, and 
Table I. Molecules associated with autophagy.

Functions

\begin{tabular}{lll}
\cline { 2 - 3 } Molecules & Breast cancer & Breast CSCs \\
\hline
\end{tabular}

mTOR With an increased amount of protein synthesis and increased inhibition of autophagy, the activation of mTOR complexes can promote the growth of tumors. Research has generally demonstrated that activated mTOR signaling increases tumor progression and often decreases patient survival. High mTOR expression is associated with poor prognosis in patients with breast cancer

ULK1 Expression of the kinase-dead ULK1 mutant K46N induced by hypoxia inhibits autophagy and increases lung metastases in MDA-MB-231 xenograft tumor mouse models. Similarly, the expression of the dominant-negative mutant of ULK1, ATG4b or ULK1-shRNA enhances cell migration in vitro

FIP200 FIP200, as a component of the ULK1-ATG13FIP200-ATG101 complex, has been demonstrated to be important for autophagosome formation. FIP200 deficiency can decrease tumor initiation and progression by disrupting tumor cell proliferation and increasing immune surveillance in an MMTV-PyMT mouse model of human breast cancer

UVRAG Studies have reported that the interaction between UVRAG and Beclin1 can promote Vps34 complex binding to and activation by Beclin 1 through its coiled-coil domain. However, research regarding the UVRAG-knockout or conditional-knockout mouse is currently unavailable

Beclin1 Complete deficiency of Beclin1 is lethal in the embryo. Mice harboring a mono-allelic deletion of Beclin1 exhibit high susceptibility to mammary hyperplasia and an increased incidence of spontaneous tumors at various sites. Studies have reported that the allelic deletion of the autophagy regulator Beclin1 led to Beclin1 loss, and likely to defective autophagy in breast cancer

ATG3 Anticancer drugs may induce autophagy in breast cancer-associated ATG3

ATG4 ATG4 proteases are well known for their crucial roles in the lipidation and delipidation of LC3 during the autophagy process. Some studies have recently shown that abnormal expression levels of some human ATG4 proteins occur in several types of cancer cells, which may be closely associated with tumor progression, tumor suppression and resistance to cancer therapy

ATG5 Mice with a mosaic deletion of ATG5 exhibit an increased incidence of tumors. The knockdown ATG5 is associated with the inhibition of autophagy in melanoma cells. The progression-free survival of patients with melanoma negatively correlates with ATG5 expression
Increasingly, research has connected mTOR activity to a phenotype of stem cell-like cancer, which can mediate breast cancer metastasis. In addition, studies have confirmed that the inhibition of mTORC $1 / 2$ can spare a cell population with stem cell-like properties and facilitate Notch activity in triple-negative breast cancer cell lines

Targeting AMPK-ULK1-mediated autophagy can combat resistance to BET inhibitor in acute myeloid leukemia stem cells, which demonstrates that ULK1-mediated autophagy can maintain the activity of stem cells

Deletion of FIP200 (Rblccl) decreases tumor development and progression in MMTV-PyMTdriven mammary tumors and does not affect the percentage of $\mathrm{ALDH}^{+}$breast CSCs. However, it significantly reduces the CD29 ${ }^{\mathrm{h}} \mathrm{iCD} 61^{+}$breast cancer CSCs in comparison with isogenic (vehicle-treated) control cells

UVRAG deficiency leads to uncontrolled proliferation and impaired differentiation without preventing autophagy in Drosophila intestinal stem cells. However, the association between UVRAG and breast CSCs is not yet clear

Gong et al showed that the expression of Beclin1 (an autophagy protein) was increased in mammospheres derived from human breast cancer. Similar findings were observed in other breast cancer cell lines (MCF-7, BT474). This study highlights a role of the autophagic pathway for CSC maintenance

ATG3-dependent autophagy is essential for mitochondrial remodeling during somatic cell reprogramming and regulating mitochondrial homeostasis in embryonic stem cells

Silencing of ATG4C impairs mammosphere formation in breast cancer

Chaterjee et al showed that the autophagy marker, (70-72) ATG5, was overexpressed in dormant stem cell-like breast cancer cells 
Table I. Continued.

Functions

\begin{tabular}{llll}
\cline { 2 - 3 } Molecules & Breast cancer & Breast CSCs \\
\hline
\end{tabular}

ATG7 ATG7 is essential for autophagy based on controlling Knockdown of ATG7 modifies the CD44 ${ }^{+} / \mathrm{CD} 24^{\text {low }}$ the formation of autophagosomes. The upregulation population in breast cancer cells by regulating of ATG7 has been observed in various cancer tissues, CD24 and IL-6 secretion including breast mammary tissue. ATG7-dependent autophagy protects breast cancer cells against mitoquinone mesylate-induced oxidative stress, which exerts a cytoprotective effect. This leads to resistance chemotherapy in breast cancer

ATG10 Genetic variants in ATG10 may be associated with breast cancer susceptibility in the Chinese population

ATG12 Studies have suggested that the ATG12 transcript is commonly upregulated in trastuzumab-unresponsive HER2-overexpressing breast cancer cells by analyzing the transcriptional status of ATG12 in $>50$ breast cancer cell lines. Significantly, in an ATG12-deficient genetic background, the growth of trastuzumab-unresponsive tumors was prevented completely following trastuzumab therapy

LC3 Knocking down autophagy-related genes LC-3, Atg12 and Beclin1 can suppress tumor formation, including breast cancer

ATG10 may provide tumor stromal support when it activates autophagy in mesenchymal stem cells

ATG12, an activator of autophagy, provides tumor $(76,77)$ stromal support in mesenchymal SCs

LC3 suppresses CSCs, which are associated with the progression of autophagy in TNBC. The level of autophagy is low in CSCs/progenitor cells during the progression and development of TNBC. The $\mathrm{LC}^{-} / \mathrm{CD} 44^{+} / \mathrm{CD} 24^{- \text {llow }}$

immunophenotype indicates a highly aggressive TNBC subgroup associated with a poor prognosis. LC3 deficiency may restrain TNBC in mature tumor cells and CSCs. Therefore, an effective therapeutic strategy in TNBC may involve the induction of autophagy

CSCs, cancer stem cells; ULK1, UNC-51-like autophagy-activating kinase; FAK200, FAK family-interacting protein of 200 kDa; UVRAG, ultraviolet irradiation resistant-associated gene; ATG, autophagy-related protein; LC3, light chain 3.

thus cannot be treated with endocrine or anti-prognosis when compared to other tumor subtypes. TNBC is believed to be invasive. Some studies have reported that radiotherapy is effective for TNBC treatment, although the treatment effects are limited $(96,97)$. There are a large amount of factors, including autophagy that can lead to limited therapeutic effects. Thus, the development of novel therapeutic strategies is essential for TNBC therapy. For example, Liu et al demonstrated that the inhibition of autophagy led to low levels of Chk1, which impaired the DNA repair capacity and diminished the ability to repair DNA double-strand breaks via homologous recombination (98). Zhou et al demonstrated that MK-8776, an inhibitor of Chk1 increased the radiosensitivity of TNBC cell lines by inhibiting autophagy in vitro. MK-8776 may have potential as a radiotherapy sensitization agent (99). Insulin-like growth factor (IGF)-1 receptor (IGF-1R) activated by binding IGF-1 results in cell proliferation, metastasis and drug resistance, and IGF-1R promotes the survival and proliferation of TNBC cell lines (100). NVP-AEW541, an inhibitor of IGF-1R, inhibits TNBC cell proliferation and induces autophagy. The role of autophagy induced by NVP-AEW541 is unclear. However, subsequent results have confirmed that the inhibition of autophagy enhances NVP-AEW541-induced cell growth suppression and the apoptosis of TNBC cells (101). Recently, autophagy has been reported to function both as a tumor suppressor mechanism and a survival mechanism, according to the tumor cell context. Saltinducible kinase 2 (a member of the AMPK family; SIK2) is essential for survival, particularly in the claudin-low subtype. It has been reported that SIK2 restrains the autophagic flux to support TNBC survival (102). Furthermore, excessive autophagic cell death may provide a novel therapeutic approach for cancer therapy instead of the induction of apoptosis. Gao et al 
Table II. Inhibitors of autophagy.

Functions

\begin{tabular}{llll}
\cline { 2 - 3 } Compounds & Breast cancer & Breast CSCs \\
\hline
\end{tabular}

Chloroquine (CQ) CQ affects the fusion between autophagosomes In a mouse model, CQ inhibits CSCs, induces autophagosomes and lysosomes, which can apoptosis and inhibits tumor formation. inhibit autophagy. The combination of CQ with other anticancer drugs can increase the apoptosis of breast cancer cells

Besides, CQ can inhibit autophagy-related gene expression

3-Methyladenine

(3-MA)

3-MA blocks the formation of autophagosomes The combination of 3-MA with other anticancer drugs can increase the apoptosis of breast cancer cells

Paclitaxel

Salinomycin

Mefloquine

Verteporfin

Quinacrine

BAY11

ARN5187

ZPCK
Paclitaxel blocks the fusion of autophagosomes with lysosomes or affects lysosomal proteolysis. Paclitaxel also induces apoptosis in breast cancer Salinomycin blocks the autophagic flux and lysosomal proteolytic activity in both CSCs and non-CSCs derived from breast cancer cells. Salinomycin induces apoptosis in breast cancer Mefloquine inhibits autophagy, and induces breast cancer cell death

Verteporfin inhibits autophagy. Verteporfininduced high molecular weight protein complexes require the presence of light Quinacrine inhibits lysosome acidification. Quinacrine effectively kills/inhibits the proliferation of cancer cells

BAY11 can inhibit autophagy. BAY11-7028, an inhibitor of NF- $\kappa \mathrm{B}$, can mimic the effect of G-1 to suppress IL-6 and VEGF-A, and inhibit migration and angiogenesis in TNBC

4-[[[1-(2-fluorophenyl)cyclopentyl]amino] methyl]-2-[(4-methylpiperazin-1-yl)methyl] phenol, 1 (ARN5187) is a novel dual inhibitor of REV-ERB $\beta$ and autophagy. ARN5187 enhances the cytotoxic effects against BT-474 breast cancer cells compared with $\mathrm{CQ}$ ZPCK inhibits cargo degradation inside the vacuole
3-MA treatment significantly suppresses bone marrow mesenchymal stem cells derived from patients with multiple myeloma (MM-MSCs)induced resistance, which indicates that autophagy sustains the activity of CSCs. It is suggested that 3-MA can maintain the activity of MM-MSCs. However, whether it can sustain the activity of breast CSCs needs to be clarified

Paclitaxel reduces the proportion of breast CSCs

Salinomycin has recently been shown to reduce the proportion of breast CSCs

Mefloquine may impair the ability of neoplastic self-renewal of human CSCs

Verteporfin can eliminate cancer stem-like cells

Quinacrine induces the apoptosis of metastatic breast CSCs

There is no relevant research which describes the role of BAY11 in breast CSCs. Thus, the function of BAY11 needs to be confirmed, which is believed to play an essential role in breast cancer treatment

There is no research on the role of ARN5187 in breast CSCs

There is no research regarding the functions of ZPCK in breast cancer and breast CSCs, but it may be a novel route for breast cancer therapy

CQ, chloroquine; 3-MA, 3-methyladenine; $N F-\kappa B$, nuclear factor- $\kappa \mathrm{B}$.

demonstrated that small-molecule RL71 triggered excessive autophagic cell death as a potential therapeutic strategy in TNBC (103).
Autophagy and luminal breast cancer. Luminal breast cancer (Luminal A, Luminal B) accounts for 50-60\% of all breast cancer cases. Although Luminal BC is sensitive to anticancer 
Table III. Summary of the effects of autophagy-associated agents on cell growth in different types of breast cancer.

\begin{tabular}{|c|c|c|c|c|}
\hline Agents/factors & Breast cancer cells & Autophagy target & Function of agents & (Refs.) \\
\hline CQ & $\begin{array}{l}\text { MCF-7, MDA-MB-231 } \\
\text { BT-47D, SKBR3 and } \\
\text { JIMT-1 cells }\end{array}$ & Inhibits lysosomal functions & Inhibits cell growth & $(96,112,113)$ \\
\hline 3-MA & $\begin{array}{l}\text { MCF-7, MDA-MB-231, } \\
\text { MDA-MB-468, BT474 } \\
\text { and AU565 cells }\end{array}$ & PI3KC3 & Inhibits cell growth & $(114-116)$ \\
\hline Bafilomycin A1 & $\begin{array}{l}\text { MDA-MB-231, MDA-MB-468 } \\
\text { and SKBR3 cells }\end{array}$ & Inhibits lysosomal functions & Inhibits cell growth & $(117,118)$ \\
\hline siRNA against ATG 7 & MCF-7 cells & $\begin{array}{l}\text { Inhibits lysosomal functions, } \\
\text { ATG } 7\end{array}$ & Inhibits cell growth & $(119)$ \\
\hline siRNA against ATG 12 & SKBR3 and JIMT1 cells & Inhibits lysosomal functions & Inhibits cell growth & $(77)$ \\
\hline PD98059 & MCF-7 and MDA-MB-231 cells & ERK1/2 pathway & Inhibits cell growth & $(120)$ \\
\hline Cantharidin & $\begin{array}{l}\text { MDA-MB-231 and } \\
\text { MDA-MB-468 cells }\end{array}$ & $\begin{array}{l}\text { Inhibits the conversion of } \\
\text { LC3I to LC3II }\end{array}$ & Inhibits cell growth & $(121)$ \\
\hline siRNAs against Beclin1 & MCF-7R cells & Inhibit Beclin 1 & Inhibit cell growth & $(122)$ \\
\hline
\end{tabular}

therapy, a conspicuous proportion of patients with breast will gradually develop resistance to anticancer therapy and relapse. Autophagy is deemed to play a critical role in response to resistance to therapy. For example, adriamycin, a first-line chemotherapeutic agent, plays an essential role in cancer. However, a high basal level of autophagy was demonstrated in adriamycin-resistant MCF-7 cells, and the silencing of TRPC5 (an inducer of autophagy) and the inhibition of autophagy reversed the resistance to adriamycin (104). Resistin is a novel adipokine that is upregulated in patients with breast cancer and promotes breast cancer cell growth, invasion and migration. In a previous study, resistin via an increased level of autophagy, inhibited the doxorubicin-induced apoptosis of MCF-7 cells (105). In addition, autophagy seems to play a dual role in luminal breast cancer, as well as TNBC. Autophagic cell death is characterized by an extensive sequestrated cytoplasm, resulting in cell death with the formation of autophagosomes or autolysosomes. Autophagic cell death can inhibit cancer development. Researches have shown that tetrandrine increases the autophagic flux in MCF-7 cells, resulting in cell death (94). The GABARAPL1 protein belongs to the ATG8 family whose members are involved in autophagy. GABARAPL1 acts as a tumor suppressor protein associated with autophagic vesicles and regulating autophagic flux in breast cancer (106).

Autophagy and HER2-positive breast cancer. HER2-positive breast cancer accounts for approximately 20-30\% of all breast cancer cases. Anti-human epidermal growth factor 2 (HER2) therapy has been approved as a standard practice for patients with HER2-positive breast cancer, leading to the improvement of patient prognosis during the past decade. However, this resistance to anti-HER 2 treatment has been a primary issue in clinical practice. Recently, autophagy has been reported to be associated with resistance to therapy. For example, autophagy protects from cytotoxicity induced by trastuzumab in breast cancer with HER2 overexpression (107). Beclin1 (also known as Becn-1), an autophagy-related gene, is important to initiate the phases of autophagy. Researches have demonstrated that a deficiency of Becn-1 enhances the sensitivity to HER2-targeted therapy, implying that the inhibition of autophagy in conjunction with HER2 inhibition is critical for promoting tumor regression, and that autophagy stimulation can transform the effectiveness of HER2 treatments (108). In parallel with these results, the knockdown ATG12 has been shown to suppress tumor growth and to sensitize trastuzumab-resistant xenografts to trastuzumab (77). The ability of chloroquine to block autophagy by inhibiting lysosomal proteases and preventing the fusion between autophagosomes and autolysosomes has established chloroquine as the most widely used drug for the inhibition of autophagy in vitro and in vivo. Connecting chloroquine with trastuzumab-based regimens may therefore improve outcomes among women with autophagy-addicted HER2-positive breast cancer (109).

In addition, we summarized the inhibitors of autophagy in different breast cancer cell lines (Table III). A recent study demonstrated that the level of autophagy differed between different subtypes of breast cancer. TNBC had substantially more autophagosomes than other types of breast cancer. Basal autophagy was high and was not influenced by chemotherapy in MDA-MB-231 cells. The expression of LC3b was similar in the control group and chemotherapy group. Compared with the MDA-MB-231 cells, basal autophagy was low in the MCF-7 cells and increased with chemotherapy (110). Treatment with chloroquine may lead to synergistic effects with chemotherapy. The combination treatment between doxorubicin and chloroquine has exhibited synergistic effects in TNBC compared 
with MCF-7 cells. TNBC cell lines showed significantly higher levels of activated STAT3 by Tyr phosphorylation than the luminal cell lines. These cells were believed to be STAT3dependent. The inhibition of autophagy decreased STAT3 phosphorylation in TNBC cell lines, and this reduction in STAT3 activity induced cell death. The inhibition of autophagy was more effective in TNBC than luminal cell lines (111).

\section{Conclusion}

In conclusion, autophagy is regulated by a complex network of stress responses. The function of autophagy in breast cancer remains unclear. Autophagy can be reduced at various developmental and metastatic phases of breast cancer, and $\mathrm{cn}$ even be a primary cell death pathway in some tumors with apoptosis deficiency. By contrast, autophagy can effectively maintain the existence of tumors under stimulation. Moreover, further research is required to elucidate the association between autophagy and breast CSCs. This review outlined the various elements and processes that are involved in the association between breast CSCs and autophagy. As these factors promote the development of tumors, their comprehensive study under different circumstances and environments is critical for the development of novel new treatment strategies for breast cancer. Autophagy seems to play an effective role in breast cancer and breast CSCs. However, its function is linked to a number of other factors, including metabolic reactions, immunoreactions and the TME. Therefore, our aim is to better understand the autophagy-related molecular mechanisms and signaling pathways, and to devote more attention to the association between breast cancer, CSCs, and autophagy. It is hoped that this will result in a meaningful strategy that could provide novel approaches to breast cancer therapy.

\section{Acknowledgements}

The authors would like to apologize to the many authors whose studies are important, but could not be cited due to space limitations. We are grateful for the members of the Department of Pathology of Dalian Medical University for their helpful discussions and suggestions during the course of this study.

\section{Competing interests}

The authors declare that they have no competing interests.

\section{References}

1. Dandawate PR, Subramaniam D, Jensen RA and Anant S Targeting cancer stem cells and signaling pathways by phytochemicals: Novel approach for breast cancer therapy. Semin Cancer Biol 40-41: 192-208, 2016.

2. Vessoni AT, Filippi-Chiela EC,Menck CF and Lenz G: Autophagy and genomic integrity. Cell Death Differ 20: 1444-1454, 2013.

3. Mizushima N, Levine B, Cuervo AM and Klionsky DJ: Autophagy fights disease through cellular self-digestion. Nature 451: 1069-1075, 2008.

4. Mowers EE, Sharifi MN and Macleod KF: Autophagy in cancer metastasis. Oncogene 36: 1619-1630, 2017.

5. Ruocco N, Costantini S and Costantini M: Blue-print autophagy: Potential for cancer treatment. Mar Drugs 14: 14, 2016.

6. Wang $\mathrm{C}, \mathrm{Hu} \mathrm{Q}$ and Shen HM: Pharmacological inhibitors of autophagy as novel cancer therapeutic agents. Pharmacol Res 105: 164-175, 2016.
7. Lee JS, Kim YJ, Kim CL and Lee GM: Differential induction of autophagy in caspase-3/7 down-regulating and Bcl-2 overexpressing recombinant $\mathrm{CHO}$ cells subjected to sodium butyrate treatment. J Biotechnol 161: 34-41, 2012.

8. Knutson BA: Insights into the domain and repeat architecture of target of rapamycin. J Struct Biol 170: 354-363, 2010.

9. Sauer E, Imseng S, Maier T and Hall MN: Conserved sequence motifs and the structure of the mTOR kinase domain. Biochem Soc Trans 41: 889-895, 2013.

10. Yang H, Rudge DG, Koos JD, Vaidialingam B, Yang HJ and Pavletich NP: mTOR kinase structure, mechanism and regulation. Nature 497: 217-223, 2013.

11. Kim DH, Sarbassov DD, Ali SM, Latek RR, Guntur KV, Erdjument-Bromage H, Tempst P and Sabatini DM: GbetaL, a positive regulator of the rapamycin-sensitive pathway required for the nutrient-sensitive interaction between raptor and mTOR. Mol Cell 11: 895-904, 2003.

12. Kaizuka T, Hara T, Oshiro N, Kikkawa U, Yonezawa K, Takehana K, Iemura S, Natsume T and Mizushima N: Ttil and Tel2 are critical factors in mammalian target of rapamycin complex assembly. J Biol Chem 285: 20109-20116, 2010.

13. Takai H, Wang RC, Takai KK, Yang H and de Lange T: Tel2 regulates the stability of PI3K-related protein kinases. Cell 131: 1248-1259, 2007

14. Peterson TR, Laplante M, Thoreen CC, Sancak Y, Kang SA, Kuehl WM, Gray NS and Sabatini DM: DEPTOR is an mTOR inhibitor frequently overexpressed in multiple myeloma cells and required for their survival. Cell 137: 873-886, 2009.

15. Wullschleger S, Loewith R and Hall MN: TOR signaling in growth and metabolism. Cell 124: 471-484, 2006.

16. Mammucari C, Milan G, Romanello V, Masiero E, Rudolf R, Del Piccolo P, Burden SJ, Di Lisi R, Sandri C, Zhao J, et al: FoxO3 controls autophagy in skeletal muscle in vivo. Cell Metab 6: 458-471, 2007

17. Zhao J, Brault JJ, Schild A, Cao P, Sandri M, Schiaffino S, Lecker SH and Goldberg AL: FoxO3 coordinately activates protein degradation by the autophagic/lysosomal and proteasomal pathways in atrophying muscle cells. Cell Metab 6: 472-483, 2007.

18. Moscat J and Diaz-Meco MT: p62 at the crossroads of autophagy, apoptosis, and cancer. Cell 137: 1001-1004, 2009.

19. Sancak Y, Bar-Peled L, Zoncu R, Markhard AL, Nada S and Sabatini DM: Ragulator-Rag complex targets mTORC1 to the lysosomal surface and is necessary for its activation by amino acids. Cell 141: 290-303, 2010.

20. Sancak Y, Peterson TR, Shaul YD, Lindquist RA, Thoreen CC, Bar-Peled L and Sabatini DM: The Rag GTPases bind raptor and mediate amino acid signaling to mTORC1. Science 320: 14961501, 2008

21. Zoncu R, Bar-Peled L, Efeyan A, Wang S, Sancak Y and Sabatini DM: mTORC1 senses lysosomal amino acids through an inside-out mechanism that requires the vacuolar $\mathrm{H}(+)$-ATPase. Science 334: 678-683, 2011.

22. Settembre C, Zoncu R, Medina DL, Vetrini F, Erdin S, Erdin S, Huynh T, Ferron M, Karsenty G, Vellard MC, et al: A lysosometo-nucleus signalling mechanism senses and regulates the lysosome via mTOR and TFEB. EMBO J 31: 1095-1108, 2012.

23. Copetti T, Bertoli C, Dalla E, Demarchi F and Schneider C: p65/ RelA modulates BECN1 transcription and autophagy. Mol Cell Biol 29: 2594-2608, 2009.

24. Lu C, Wang W, Jia Y, Liu X, Tong Z and Li B: Inhibition of AMPK/autophagy potentiates parthenolide-induced apoptosis in human breast cancer cells. J Cell Biochem 115: 1458-1466, 2014.

25. Al-Hajj M, Wicha MS, Benito-Hernandez A, Morrison SJ and Clarke MF: Prospective identification of tumorigenic breast cancer cells. Proc Natl Acad Sci USA 100: 3983-3988, 2003.

26. Abdal Dayem A, Choi HY, Yang GM, Kim K, Saha SK and Cho SG: The anti-cancer effect of polyphenols against breast cancer and cancer stem cells: Molecular mechanisms. Nutrients 8: 581-618, 2016.

27. Ricardo S, Vieira AF, Gerhard R, Leitão D, Pinto R, CameselleTeijeiro JF, Milanezi F, Schmitt F and Paredes J: Breast cancer stem cell markers CD44, CD24 and ALDH1: Expression distribution within intrinsic molecular subtype. J Clin Pathol 64: 937-946, 2011.

28. Idowu MO, Kmieciak M, Dumur C, Burton RS, Grimes MM, Powers CN and Manjili MH: CD44(+)/CD24(-/low) cancer stem/ progenitor cells are more abundant in triple-negative invasive breast carcinoma phenotype and are associated with poor outcome. Hum Pathol 43: 364-373, 2012. 
29. Ahmed MA, Aleskandarany MA, Rakha EA, Moustafa RZ, Benhasouna A, Nolan C, Green AR, Ilyas M and Ellis IO: A CD $44^{-} / \mathrm{CD} 24^{+}$phenotype is a poor prognostic marker in early invasive breast cancer. Breast Cancer Res Treat 133: 979-995, 2012.

30. Fonseca NA, Cruz AF, Moura V, Simões S and Moreira JN: The cancer stem cell phenotype as a determinant factor of the heterotypic nature of breast tumors. Crit Rev Oncol Hematol 113: 111-121, 2017.

31. Ingham PW and McMahon AP: Hedgehog signaling in animal development: Paradigms and principles. Genes Dev 15 3059-3087, 2001

32. McMahon AP, Ingham PW and Tabin CJ: Developmental roles and clinical significance of hedgehog signaling. Curr Top Dev Biol 53: 1-114, 2003

33. Murone M, Rosenthal A and de Sauvage FJ: Sonic hedgehog signaling by the patched-smoothened receptor complex. Curr Biol 9: 76-84, 1999.

34. Bray SJ: Notch signalling: A simple pathway becomes complex. Nat Rev Mol Cell Biol 7: 678-689, 2006.

35. Ishii H, Iwatsuki M, Ieta K, Ohta D, Haraguchi N, Mimori K and Mori M: Cancer stem cells and chemoradiation resistance. Cancer Sci 99: 1871-1877, 2008.

36. Wang M, Zhang J, Huang Y, Ji S, Shao G, Feng S, Chen D, Zhao K, Wang Z and Wu A: Cancer-associated fibroblasts autophagy enhances progression of triple-negative breast cancer cells. Med Sci Monit 23: 3904-3912, 2017.

37. Sun R, Shen S, Zhang YJ, Xu CF, Cao ZT, Wen LP and Wang J: Nanoparticle-facilitated autophagy inhibition promotes the efficacy of chemotherapeutics against breast cancer stem cells Biomaterials 103: 44-55, 2016

38. Liang DH, Choi DS, Ensor JE, Kaipparettu BA, Bass BL and Chang JC: The autophagy inhibitor chloroquine targets cancer stem cells in triple negative breast cancer by inducing mitochondrial damage and impairing DNA break repair. Cancer Lett 376: 249-258, 2016.

39. Bincoletto C, Bechara A, Pereira GJS, Santos CP, Antunes F, Peixoto da-Silva J, Muler M, Gigli RD, Monteforte PT, Hirata H, et al: Interplay between apoptosis and autophagy, a challenging puzzle: New perspectives on antitumor chemotherapies. Chem Biol Interact 206: 279-288, 2013

40. Yousefi S, Perozzo R, Schmid I, Ziemiecki A, Schaffner T, Scapozza L, Brunner T and Simon HU: Calpain-mediated cleavage of Atg5 switches autophagy to apoptosis. Nat Cell Biol 8: $1124-1132,2006$

41. DeNardo DG, Barreto JB, Andreu P, Vasquez L, Tawfik D, Kolhatkar N and Coussens LM: CD4(+) T cells regulate pulmonary metastasis of mammary carcinomas by enhancing protumor properties of macrophages. Cancer Cell 16: 91-102, 2009.

42. Mukhopadhyay S, Panda PK, Sinha N, Das DN and Bhutia SK Autophagy and apoptosis: Where do they meet? Apoptosis 19 555-566, 2014

43. Yao D, Wang $\mathrm{P}$, Zhang J, Fu L, Ouyang L and Wang J: Deconvoluting the relationships between autophagy and metastasis for potential cancer therapy. Apoptosis 21: 683-698, 2016.

44. Han Q, Deng Y, Chen S, Chen R, Yang M, Zhang Z, Sun X, Wang W, He Y, Wang F, et al: Downregulation of ATG5dependent macroautophagy by chaperone-mediated autophagy promotes breast cancer cell metastasis. Sci Rep 7: 4759, 2017.

45. Kongara S, Kravchuk O, Teplova I, Lozy F, Schulte J, Moore D, Barnard N, Neumann CA, White E and Karantza V: Autophagy regulates keratin 8 homeostasis in mammary epithelial cells and in breast tumors. Mol Cancer Res 8: 873-884, 2010.

46. Kuraishy A, Karin M and Grivennikov SI: Tumor promotion via injury- and death-induced inflammation. Immunity 35: 467-477, 2011 .

47. Kung CP, Budina A, Balaburski G, Bergenstock MK and Murphy M: Autophagy in tumor suppression and cancer therapy. Crit Rev Eukaryot Gene Expr 21: 71-100, 2011.

48. White E and DiPaola RS: The double-edged sword of autophagy modulation in cancer. Clin Cancer Res 15: 5308-5316, 2009.

49. Choi KS: Autophagy and cancer. Exp Mol Med 44: 109-120, 2012.

50. Denton D, Nicolson S and Kumar S: Cell death by autophagy: Facts and apparent artefacts. Cell Death Differ 19: 87-95, 2012.

51. Maycotte P, Jones KL, Goodall ML, Thorburn J and Thorburn A: Autophagy supports breast cancer stem cell maintenance by regulating IL6 secretion. Mol Cancer Res 13: 651-658, 2015.
52. Wolf J, Dewi DL, Fredebohm J, Müller-Decker K, Flechtenmacher C, Hoheisel JD and Boettcher M: A mammosphere formation RNAi screen reveals that ATG4A promotes a breast cancer stem-like phenotype. Breast Cancer Res 15: R109, 2013.

53. Gong C, Bauvy C, Tonelli G, Yue W, Deloménie C, Nicolas V, Zhu Y, Domergue V, Marin-Esteban V, Tharinger $\mathrm{H}$, et al: Beclin 1 and autophagy are required for the tumorigenicity of breast cancer stem-like/progenitor cells. Oncogene 32: 2261-2272, 1-11, 2013.

54. Zhao Y, Huang Q, Yang J, Lou M, Wang A, Dong J, Qin Z and Zhang T: Autophagy impairment inhibits differentiation of glioma stem/progenitor cells. Brain Res 1313: 250-258, 2010.

55. Singh BN, Kumar D, Shankar S and Srivastava RK: Rottlerin induces autophagy which leads to apoptotic cell death through inhibition of PI3K/Akt/mTOR pathway in human pancreatic cancer stem cells. Biochem Pharmacol 84: 1154-1163, 2012.

56. Kumar D, Shankar S and Srivastava RK: Rottlerin-induced autophagy leads to the apoptosis in breast cancer stem cells: Molecular mechanisms. Mol Cancer 12: 171, 2013.

57. Wei MF, Chen MW, Chen KC, Lou PJ, Lin SY, Hung SC, Hsiao M, Yao CJ and Shieh MJ: Autophagy promotes resistance to photodynamic therapy-induced apoptosis selectively in colorectal cancer stem-like cells. Autophagy 10: 1179-1192, 2014.

58. Yue W, Hamaï A, Tonelli G, Bauvy C, Nicolas V, Tharinger H, Codogno $\mathrm{P}$ and Mehrpour M: Inhibition of the autophagic flux by salinomycin in breast cancer stem-like/progenitor cells interferes with their maintenance. Autophagy 9: 714-729, 2013.

59. Chiang GG and Abraham RT: Targeting the mTOR signaling network in cancer. Trends Mol Med 13: 433-442, 2007.

60. Xu K, Liu P and Wei W: mTOR signaling in tumorigenesis. Biochim Biophys Acta 1846: 638-654, 2014.

61. Mateo F, Arenas EJ, Aguilar H, Serra-Musach J, de Garibay GR, Boni J, Maicas M, Du S, Iorio F, Herranz-Ors C, et al: Stem cell-like transcriptional reprogramming mediates metastatic resistance to mTOR inhibition. Oncogene 36: 2737-2749, 2017.

62. Zhang L, Fu L, Zhang S, Zhang J, Zhao Y, Zheng Y, He G, Yang S, Ouyang L and Liu B: Discovery of a small molecule targeting ULK1-modulated cell death of triple negative breast cancer in vitro and in vivo. Chem Sci (Camb) 8: 2687-2701, 2017

63. Jang JE, Eom JI, Jeung HK, Cheong JW, Lee JY, Kim JS and Min YH: Targeting AMPK-ULK1-mediated autophagy for combating BET inhibitor resistance in acute myeloid leukemia stem cells. Autophagy 13: 761-762, 2017.

64. Zhou Y, Rucker EB III and Zhou BP: Autophagy regulation in the development and treatment of breast cancer. Acta Biochim Biophys Sin (Shanghai) 48: 60-74, 2016.

65. Yeo SK, Wen J, Chen S and Guan JL: Autophagy differentially regulates distinct breast cancer stem-like cells in murine models via EGFR/Stat 3 and $\operatorname{Tgf} \beta /$ Smad signaling. Cancer Res 76 : 3397-3410, 2016.

66. Nagy P, Kovács L, Sándor GO and Juhász G: Stem-cell-specific endocytic degradation defects lead to intestinal dysplasia in Drosophila. Dis Model Mech 9: 501-512, 2016.

67. Liu K, Zhao Q, Liu P, Cao J, Gong J, Wang C, Wang W, Li X, Sun $\mathrm{H}$, Zhang C, et al: ATG3-dependent autophagy mediates mitochondrial homeostasis in pluripotency acquirement and maintenance. Autophagy 12: 2000-2008, 2016.

68. Zhang L, Li J, Ouyang L, Liu B and Cheng Y: Unraveling the roles of Atg 4 proteases from autophagy modulation to targeted cancer therapy. Cancer Lett 373: 19-26, 2016.

69. Antonelli M, Strappazzon F, Arisi I, Brandi R, D'Onofrio M, Sambucci M, Manic G, Vitale I, Barilà D and Stagni V: ATM kinase sustains breast cancer stem-like cells by promoting ATG4C expression and autophagy. Oncotarget 8: 21692-21709, 2017.

70. Liu H, He Z, von Rütte T, Yousefi S, Hunger RE and Simon HU: Down-regulation of autophagy-related protein 5 (ATG5) contributes to the pathogenesis of early-stage cutaneous melanoma. Sci Transl Med 5: 202ra123, 2013.

71. Debnath J: The multifaceted roles of autophagy in tumorsimplications for breast cancer. J Mammary Gland Biol Neoplasia 16: 173-187, 2011.

72. Chaterjee M and van Golen KL: Breast cancer stem cells survive periods of farnesyl-transferase inhibitor-induced dormancy by undergoing autophagy. Bone Marrow Res 2011: 362938, 2011.

73. Memni H, Macherki Y, Klayech Z, Ben-Haj-Ayed A, Farhat K, Remadi Y, Gabbouj S, Mahfoudh W, Bouzid N, Bouaouina N, et al: E-cadherin genetic variants predict survival outcome in breast cancer patients. J Transl Med 14: 320, 2016. 
74. Zhuang W, Li B, Long L, Chen L, Huang Q and Liang Z: Induction of autophagy promotes differentiation of glioma-initiating cells and their radiosensitivity. Int J Cancer 129: 2720-2731, 2011.

75. Qin Z, Xue J, He Y, Ma H, Jin G, Chen J, Hu Z, Liu X and Shen H: Potentially functional polymorphisms in ATG10 are associated with risk of breast cancer in a Chinese population. Gene 527: 491-495, 2013.

76. Sanchez CG,Penfornis P, Oskowitz AZ, Boonjindasup AG, Cai DZ, Dhule SS, Rowan BG, Kelekar A, Krause DS and Pochampally RR: Activation of autophagy in mesenchymal stem cells provides tumor stromal support. Carcinogenesis 32: 964-972, 2011.

77. CufíS, Vazquez-Martin A, Oliveras-Ferraros C, Corominas-Faja B, Urruticoechea A, Martin-Castillo B and Menendez JA: Autophagy-related gene 12 (ATG12) is a novel determinant of primary resistance to HER2-targeted therapies: Utility of transcriptome analysis of the autophagy interactome to guide breast cancer treatment. Oncotarget 3: 1600-1614, 2012.

78. Chang SJ, Ou-Yang F, Tu HP, Lin CH, Huang SH, Kostoro J, Hou MF, Chai CY and Kwan AL: Decreased expression of autophagy protein LC3 and stemness (CD44+/CD24\%/low) indicate poor prognosis in triple-negative breast cancer. Hum Pathol 48: 48-55, 2016.

79. Carpenter RL, Sirkisoon S, Zhu D, Rimkus T, Harrison A, Anderson A, Paw I, Qasem S, Xing F, Liu Y, et al: Combined inhibition of AKT and HSF1 suppresses breast cancer stem cells and tumor growth. Oncotarget 8: 73947-73963, 2017.

80. Petherick KJ, Williams AC, Lane JD, Ordóñez-Morán P, Huelsken J, Collard TJ, Smartt HJ, Batson J, Malik K, Paraskeva C, et al: Autolysosomal $\beta$-catenin degradation regulates Wnt-autophagy-p62 crosstalk. EMBO J 32: 1903-1916, 2013.

81. Wang Y, Han C, Lu L, Magliato S and Wu T: Hedgehog signaling pathway regulates autophagy in human hepatocellular carcinoma cells. Hepatology 58: 995-1010, 2013.

82. Espina V and Liotta LA: What is the malignant nature of human ductal carcinoma in situ? Nat Rev Cancer 11: 68-75, 2011.

83. Yang H, Zheng Y, Zhang Y, Cao Z and Jiang Y: Mesenchymal stem cells derived from multiple myeloma patients protect against chemotherapy through autophagy-dependent activation of NF- $\kappa$ B signaling. Leuk Res 60: 82-88, 2017.

84. Huang S, Wang D, Zhang S, Huang X, Wang D, Ijaz M and Shi Y: Tunicamycin potentiates paclitaxel-induced apoptosis through inhibition of PI3K/AKT and MAPK pathways in breast cancer. Cancer Chemother Pharmacol 80: 685-696, 2017.

85. Sharma N, Thomas S, Golden EB, Hofman FM, Chen TC, Petasis NA, Schönthal AH and Louie SG: Inhibition of autophagy and induction of breast cancer cell death by mefloquine, an antimalarial agent. Cancer Lett 326: 143-154, 2012.

86. Ma YW, Liu YZ and Pan JX: Verteporfin induces apoptosis and eliminates cancer stem-like cells in uveal melanoma in the absence of light activation. Am J Cancer Res 6: 2816-2830, 2016

87. Shi TT, Yu XX, Yan LJ and Xiao HT: Research progress of hydroxychloroquine and autophagy inhibitors on cancer. Cancer Chemother Pharmacol 79: 287-294, 2017.

88. Solomon VR, Almnayan D and Lee H: Design, synthesis and characterization of novel quinacrine analogs that preferentially kill cancer over non-cancer cells through the down-regulation of Bcl-2 and up-regulation of Bax and Bad. Eur J Med Chem 137: 156-166, 2017.

89. Siddharth S, Nayak D, Nayak A, Das S and Kundu CN: ABT-888 and quinacrine induced apoptosis in metastatic breast cancer stem cells by inhibiting base excision repair via adenomatous polyposis coli. DNA Repair (Amst) 45: 44-55, 2016.

90. Mishra P, Dauphinee AN, Ward C, Sarkar S, Gunawardena AHLAN and Manjithaya R: Discovery of pan autophagy inhibitors through a high-throughput screen highlights macroautophagy as an evolutionarily conserved process across 3 eukaryotic kingdoms. Autophagy 13: 1556-1572, 2017.

91. Liang S, Chen Z, Jiang G, Zhou Y, Liu Q, Su Q, Wei W, Du J and Wang H: Activation of GPER suppresses migration and angiogenesis of triple negative breast cancer via inhibition of NF-KB/ IL-6 signals. Cancer Lett 386: 12-23, 2017.

92. Torrente E, Parodi C, Ercolani L, De Mei C, Ferrari A, Scarpelli R and Grimaldi B: Synthesis and in vitro anticancer activity of the first cass of dual inhibitors of REV-ERB $\beta$ and autophagy. J Med Chem 58: 5900-5915, 2015.

93. Zhou X, Yue GG, Chan AM, Tsui SK, Fung KP, Sun H, Pu J and Lau CB: Eriocalyxin B, a novel autophagy inducer, exerts antitumor activity through the suppression of Akt/mTOR/p70S6K signaling pathway in breast cancer. Biochem Pharmacol 142: 58-70, 2017.
94. Wong VKW, Zeng W, Chen J, Yao XJ, Leung ELH, Wang QQ, Chiu P, Ko BCB and Law BYK: Tetrandrine, an activator of autophagy, induces autophagic cell death via PKC- $\alpha$ inhibition and mTOR-dependent mechanisms. Front Pharmacol 8: 351, 2017

95. Han H, Li J, Feng X, Zhou H, Guo S and Zhou W: Autophagyrelated genes are induced by histone deacetylase inhibitor suberoylanilide hydroxamic acid via the activation of cathepsin B in human breast cancer cells. Oncotarget 8: 53352-53365, 2017.

96. Chen X, Yu X, Chen J, Yang Z, Shao Z, Zhang Z, Guo X and Feng Y: Radiotherapy can improve the disease-free survival rate in triple-negative breast cancer patients with T1-T2 disease and one to three positive lymph nodes after mastectomy. Oncologist 18: 141-147, 2013.

97. Chen X, Yu X, Chen J, Zhang Z, Tuan J, Shao Z, Guo X and Feng Y: Analysis in early stage triple-negative breast cancer treated with mastectomy without adjuvant radiotherapy: Patterns of failure and prognostic factors. Cancer 119: 2366-2374, 2013.

98. Liu EY, Xu N, O'Prey J, Lao LY, Joshi S, Long JS, O'Prey M, Croft DR, Beaumatin F, Baudot AD, et al: Loss of autophagy causes a synthetic lethal deficiency in DNA repair. Proc Natl Acad Sci USA 112: 773-778, 2015.

99. Zhou ZR, Yang ZZ, Wang SJ, Zhang L, Luo JR, Feng Y, Yu XL, Chen XX and Guo XM: The Chk1 inhibitor MK-8776 increases the radiosensitivity of human triple-negative breast cancer by inhibiting autophagy. Acta Pharmacol Sin 38: 513-523, 2017.

100. Davison Z, de Blacquière GE, Westley BR and May FEB Insulin-like growth factor-dependent proliferation and survival of triple-negative breast cancer cells: Implications for therapy. Neoplasia 13: 504-515, 2011

101. Wu W, Ma J, Shao N, Shi Y, Liu R, Li W, Lin Y and Wang S: Co-targeting IGF-1R and autophagy enhances the effects of cell growth suppression and apoptosis induced by the IGF-1R inhibitor NVP-AEW541 in triple-negative breast cancer cells. PLoS One 12: e0169229, 2017.

102. Maxfield KE, Macion J, Vankayalapati H and Whitehurst AW: SIK2 restricts autophagic flux to support triple-negative breast cancer survival. Mol Cell Biol 36: 3048-3057, 2016.

103. Gao J, Fan M, Peng S, Zhang M, Xiang G, Li X, Guo W, Sun Y, Wu X, Wu X, et al: Small-molecule RL71-triggered excessive autophagic cell death as a potential therapeutic strategy in triple-negative breast cancer. Cell Death Dis 8: e3049, 2017.

104.Zhang P, Liu X, Li H, Chen Z, Yao X, Jin J and Ma X TRPC5-induced autophagy promotes drug resistance in breast carcinoma via $\mathrm{CaMKK} \beta / \mathrm{AMPK} \alpha / \mathrm{mTOR}$ pathway. Sci Rep 7: 3158,2017

105. Liu Z, Shi A, Song D, Han B, Zhang Z, Ma L, Liu D and Fan Z: Resistin confers resistance to doxorubicin-induced apoptosis in human breast cancer cells through autophagy induction. Am J Cancer Res 7: 574-583, 2017.

106. Poillet-Perez L, Jacquet M, Hervouet E, Gauthier T, Fraichard A, Borg C, Pallandre JR, Gonzalez BJ, Ramdani Y, BoyerGuittaut M, et al: GABARAPL1 tumor suppressive function is independent of its conjugation to autophagosomes in MCF-7 breast cancer cells. Oncotarget 8: 55998-56020, 2017.

107. Rodríguez CE, Reidel SI, Bal de Kier Joffé ED, Jasnis MA and Fiszman GL: Autophagy protects from trastuzumab-induced cytotoxicity in HER 2 overexpressing breast tumor spheroids. PLoS One 10: e0137920, 2015.

108. Zambrano J and Yeh ES; ZambranoJ: Autophagy and apoptotic crosstalk: Mechanism of therapeutic resistance in HER2-positive breast cncer. Breast Cancer (Auckl) 10: 13-23, 2016.

109. CufíS, Vazquez-Martin A, Oliveras-Ferraros C, Corominas-FajaB, Cuyàs E, López-Bonet E, Martin-Castillo B, Joven J and Menendez JA: The anti-malarial chloroquine overcomes primary resistance and restores sensitivity to trastuzumab in HER2positive breast cancer. Sci Rep 3: 2469, 2013.

110. Garbar C, Mascaux C, Giustiniani J, Merrouche Y and Bensussan A: Chemotherapy treatment induces an increase of autophagy in the luminal breast cancer cell MCF7, but not in the triple-negative MDA-MB231. Sci Rep 7: 7201, 2017.

111. Maycotte P, Gearheart CM, Barnard R, Aryal S, Mulcahy Levy JM, Fosmire SP, Hansen RJ, Morgan MJ, Porter CC, Gustafson DL, et al: STAT3-mediated autophagy dependence identifies subtypes of breast cancer where autophagy inhibition can be efficacious. Cancer Res 74: 2579-2590, 2014.

112. Wang S, Wang K, Wang H, Han J and Sun H: Autophagy is essential for flavopiridol-induced cytotoxicity against MCF-7 breast cancer cells. Mol Med Rep 16: 9715-9720, 2017. 
113. Chang CT, Korivi M, Huang HC, Thiyagarajan V, Lin KY, Huang PJ, Liu JY, Hseu YC and Yang HL: Inhibition of ROS production, autophagy or apoptosis signaling reversed the anticancer properties of Antrodia salmonea in triple-negative breast cancer (MDA-MB-231) cells. Food Chem Toxicol 103: 1-17, 2017.

114.Zheng N, Liu L, Liu WW, Li F, Hayashi T, Tashiro SI, Onodera S and Ikejima T: Crosstalk of ROS/RNS and autophagy in silibinin-induced apoptosis of MCF-7 human breast cancer cells in vitro. Acta Pharmacol Sin 38: 277-289, 2017

115. Liu ZY, He KW, Song XG, Wang XZ, Zhuo PY, Wang XW, Ma QH, Huo ZJ and Yu ZY: Effect of autophagy inhibitor combined with EGFR inhibitor on triple-negative breast cancer MDA-MB-468 and MDA-MB-231 cells. Zhonghua Zhong Liu Za Zhi 38: 417-424, 2016 (In Chinese)

116. Tran AT, Ramalinga M, Kedir H, Clarke R and Kumar D: Autophagy inhibitor 3-methyladenine potentiates apoptosis induced by dietary tocotrienols in breast cancer cells. Eur J Nutr 54: 265-272, 2015.

117. Liu Z, He K, Ma Q, Yu Q, Liu C, Ndege I, Wang X and Yu Z: Autophagy inhibitor facilitates gefitinib sensitivity in vitro and in vivo by activating mitochondrial apoptosis in triple negative breast cancer. PLoS One 12: e0177694, 2017.
118. Wang H, Wang W, Xu Y, Yang Y, Chen X, Quan H and Lou L Aberrant intracellular metabolism of T-DM1 confers T-DM1 resistance in human epidermal growth factor receptor 2-positive gastric cancer cells. Cancer Sci 108: 1458-1468, 2017.

119. Gong C, Hu C, Gu F, Xia Q, Yao C, Zhang L, Qiang L, Gao S and Gao Y: Co-delivery of autophagy inhibitor ATG7 siRNA and docetaxel for breast cancer treatment. J Control Release 266: 272-286, 2017.

120. Shen P, Chen M, He M, Chen L, Song Y, Xiao P, Wan X, Dai F, Pan $T$ and Wang Q: Inhibition of ER $\alpha / E R K / P 62$ cascades induces 'autophagic switch' in the estrogen receptor-positive breast cancer cells exposed to gemcitabine. Oncotarget 7: 48501-48516, 2016.

121. Li HC, Xia ZH, Chen YF, Yang F, Feng W, Cai H, Mei Y, Jiang YM, Xu K and Feng DX: Cantharidin inhibits the growth of triple-negative breast cancer cells by suppressing autophagy and inducing apoptosis in vitro and in vivo. Cell Physiol Biochem 43: 1829-1840, 2017.

122. Gu Y, Chen T, Li G, Xu C, Xu Z, Zhang J, He K, Zheng L, Guan Z, Su X, et al: Lower Beclin 1 downregulates HER2 expression to enhance tamoxifen sensitivity and predicts a favorable outcome for ER positive breast cancer. Oncotarget 8: 52156-52177, 2016. 